\title{
PROTOCOLLO DI SORVEGLIANZA PER LA NEFROPATIA DA BKV IN IIT PAZIENTI CON TRAPIANTO RENALE
}

\author{
Giraldi C., Papalia T., Greco R., Noto A., Greco F., \\ Tenuta R., Bonofiglio R.
}

\section{U.O. Nefrologia, Microbiologia e Virologia Ospedale Annunziata AO Cosenza}

\section{Introduzione}

La Nefropatia da poliomavirus BK (BKVAN) nei portatori di trapianto (tx) renale si sta imponendo, con una frequenza crescente, come una causa di prematura perdita dell'organo trapiantato. La BKVAN va quindi considerata nella diagnostica differenziale con il rigetto acuto. In questo studio prospettico proponiamo un protocollo diagnostico, non invasivo, per l'identificazione, in corso di follow-up ambulatoriale, di pazienti a rischio per infezione attiva da BKV.

\section{Materiali e Metodi}

In 117 pazienti con tx renale è stata valutata, a tempo 0-3-612-18-24 mesi dal tx, la ricerca di DNA BKV plasmatica e urinaria (PCR nested per lo screening e Real Time PCR per la quantizzazione dei campioni positivi). I pazienti sono stati suddivisi in gruppi in base delle positività per BKV su sangue e urine. Dei 117 pazienti, il 35\% sono in terapia con TAC e MMF, il $1,9 \%$ con RAPA e MMF ed il $63,1 \%$ con CYA e $\mathrm{MM} ; 5$ erano stati sottoposti a tx da vivente, il rimanente a tx da cadavere.

\section{Risultati}

Nei 117 pazienti, seguiti in un follow-up di 24 mesi, 4 $(3,4 \%)$, tutti di sesso maschile, presentavano una BKVAN (accertata istologicamente e con tecnica immunoistochimica per antigene SV40) con deterioramento della funzione renale dopo $14.6 \pm 6,1$ mesi dal trapianto. Dei 4 pazienti, uno era in terapia con $\mathrm{CyA}+\mathrm{MMF}$ e 3 con $\mathrm{FK}+\mathrm{MMF}$

I pazienti sono stati suddivisi in 7 gruppi, in base alla viruria e/o virermia. I quattro $\mathrm{pz}$ con BKVAN presentavano una viruria con carica superiore a $16.000 .000 \mathrm{cp} / \mathrm{ml} \mathrm{e}$ viremia superiore a $40.000 \mathrm{cp} / \mathrm{ml}$.

\section{Conclusioni}

La BKVAN nei trapiantati è una patologia emergente che può comportare una precoce perdita dell'organo trapiantato se non si effettua una diagnosi precoce. Il nostro protocollo di sorveglianza si è dimostrato una valida strategia per l'identificazione della nefropatia in tempi rapidi impedendo, nei 4 casi di BKVNA, la perdita dell'organo trapiantato. Viruria e viremia, identificando i pazienti a rischio per BKVAN, possono essere utilizzati come indicatori di un più oculato monitoraggio della terapia immunosoppressiva in corso di follow-up. 